\title{
ASSESSMENT OF VARK LEARNING STYLE COMPATIBILITY IN ICT MODULES ON HEALTH AND NUTRITION EDUCATION
}

\section{N.SUNITHA ${ }^{1}$, Y.UMAJYOTHI ${ }^{2}$, PRIYA SUGANDHI GEDDAM ${ }^{3} \&$ P.SREEDEVI $^{4}$}

${ }^{1}$ Research Scholar Department of Home Science Extension and Communication Management, College of Home Science, PJTSAU, Hyderabad

${ }^{2}$ Senior Research Fellow, All India Coordinated Research Project on Home Science Department of Extension PJTSAU, Hyderabad

${ }^{3}$ Research Scholar, Department of Foods and Nutrition, Post Graduate and Research Center, Rajendranagar

${ }^{4}$ Assistant Professor, Department of Human Development and Family Studies,

College of Home Science, PJTSAU, Hyderabad

ABSTRACT
The present study on the Assessment of VARK learning style compatibility of ICT modules, on Health and
Nutrition Education, the size of the sample comprises of 150, which are selected randomly from five adopted villages of
KVK, Rudrur, in Nizamabad district. The findings revealed that, ICT modules could engage the learner in learning. The
highest overall mean score was attained for the lesson anemia (19.61), followed by leafy vegetables (19.46), millets (19.43),
diabetes (19.36) and thyroidism (19.31). With regard to learning styles, respondents who use a combination of modalities
in learning (multi learning styles), got high scores (19.70), followed by learning by reading (19.58), bimodal (19.51), visual
(19.40), audio (19.26) and kinesthetic learning style (19.19). Hence, it could be inferred that, the digital lessons supported
all the learning styles and resulted in effective learning.
KEYWORDS: Learning Style, VARK-Visual, Read/Write, and Kinesthetic, ICT Modules, Health \& Nutrition Education

Received: Aug 04, 2017; Accepted: Aug 24, 2017; Published: Oct 21, 2017; Paper Id.: IJESROCT201716

\section{INTRODUCTION}

Learning style preferences change over the time. Although, after a period, the individual develops a strong style preference, that help the learner to learn easily; if taught with new styles, they complement those style preferences, after a period. Reid (1987), titled this change as "perceptual learning styles" and defined it as the changes among learners, in using one or more senses to understand, organize, and retain experience. Fleming (2001), proposed VARK the acronym for Visual (V), Aural (A), Read/Write (R), and Kinesthetic (K) Model, He defined learning style as an individual's characteristics, and preferred ways of gathering, organizing, and thinking about information.

\section{REVIEW OF LITERATURE}

Wright and Stokes (2015), reported the outcome of the application of VARK learning styles, at the teaching of introductory level of economic units, in Australian Catholic University (ACU). They adopted teaching and learning approaches, to engage students and develop skills in economics, by recognizing differences in student preferences for learning styles. They measured learning styles in terms of visual $(\mathrm{V})$, aural $(\mathrm{A})$, reading $(\mathrm{R})$ and 
kinesthetic $(\mathrm{K})$, and determined students preferred modes of in taking, processing and outputting information. Accordingly, inputs were provided incorporating VARK approaches, for developing literacy and numeracy skills in economics, information and communication skills, and critical and creative thinking skills. At ACU level, through student's evaluation of teaching surveys, the impact of the approach was measured, which was reported positive and the scores improved, from the first semester to second semester. Similarly, when compared to the average scores of students, with economics as major subject of nine universities, in New South Wales, the ACU students ranked first.

Guo (2013), opined the optimal video length, as 6 minutes or shorter, and students watched most of the way through these short videos. He further stated that, the average engagement time of any video maxes out at 6 minutes, regardless of its length and engagement times decrease, as videos lengthen. In the context of human-computer interaction and online education, he observed on average students, engaged around 3 minutes of videos, that are longer than 12 minutes, which means that, they engaged with less than a quarter of the content. Whereas, certificate-earning students engaged more with videos, presumably because, they had greater motivation to learn the material. So, to maximize student engagement, they should work with instructional designers and video producers, to break up their lectures into small, bitesized pieces.

Siragusa and Dixon (2008), conducted a pilot study to collect data from a small group of undergraduate students, in a higher education setting, to determine their attitudes towards their use and engagement of ICT interactions. The majority indicated that, interacting with ICT would result in positive outcomes, and most of the sample described a desire to feel a sense of competence, when engaging with technology. This is interesting when compared to the qualitative findings, which seemed to indicate that, at least $33 \%$ of the responses suggested that, the sample had experienced feelings of anxiety and intimidation for various reasons, when actually working through the ICT interaction. It appeared from the quantitative data that, overall, the students believed that, interacting with ICT was pleasant, helpful and easy.

Vijayaraghavan (2002), evaluated the Government of India initiated national programs to prevent, control and combat micronutrient deficiencies of vitamin A, iron, and iodine deficiencies, and their serious consequences in India and revealed that, the biological impact of these interventions was unsatisfactory. As a result of poor orientation, the functionaries were not adhering to the guidelines, leading to woefully inadequate and irregular coverage. With the adoption of National Nutrition Policy by the Government of India, he recommended for a concerted and focused approach. High lightening the future strategies, he stated innovative approaches in information, education, and communication, such as social marketing strategy, for making the interventions sustainable should be adopted.

\section{METHODOLOGY}

\section{Sample Size}

The exploratory research design was used for the present study, $(\mathrm{n}=150)$ both men and women, adults were randomly selected from five villages, i.e., Beerkur, Kistapur, Malkapur, Ranampally, and Timmapur of KVK, Rudrur, Nizambad district.

The experienced panel of judges ( $\mathrm{n}=30$ ) was selected from suggestions, in observation inventory

\section{Observation Inventory for VARK Compatibility of ICT Module on Health and Nutrition Education}

This inventory consisted of 24 items, related to the attributes essential to support VARK learning style. Among these items, 16 were positive statements and eight were negative. The judges should give their judgment, whether those 
attributes are present or not, in terms of strongly agree, agree or disagree, in which 3,2 and 1 scores are assigned respectively, for all positive statements and 1,2 and 3, for negative statements. Reliability of the inventory was also computed through test and retest method, to confirm its effectiveness.

\section{VARK Learning Style Compatibility of ICT Module}

The observation inventory has a total of 24 items, out of which eight were negative and the remaining was positive. The maximum score an individual can obtain was 72 , and minimum 24 . While watching the ICT module on health and nutrition education, the experts provided their agreement, as per the observation inventory. Mean scores were calculated and tabulated below.

Table 1: VARK Learning Style Compatibility in ICT Module n=30

\begin{tabular}{|c|c|c|c|c|c|c|}
\hline \multirow{2}{*}{ S. No. } & \multirow{2}{*}{ Item } & \multicolumn{4}{|c|}{ Mean Score } & \multirow{2}{*}{ Percentage } \\
\hline & & $\mathbf{V}$ & $\mathbf{A}$ & $\mathbf{R}$ & $\mathbf{K}$ & \\
\hline 1. & Content is aptly translated into pictures/images & 2.40 & & & & 80.00 \\
\hline 2. & The content is orally explained & & 2.67 & & & 88.89 \\
\hline 3. & Enabled uninterrupted reading & & & 2.40 & & 80.00 \\
\hline 4. & Enabled involvement of the learner & & & & 2.43 & 81.11 \\
\hline 5. & $\begin{array}{l}\text { Content is not described in understandable language } \\
\text { and words }\end{array}$ & & & 2.50 & & 83.33 \\
\hline 6. & Did not feel boredom with visual directions & 2.67 & & & & 88.89 \\
\hline 7. & Key points are highlighted & & & & 2.27 & 75.56 \\
\hline 8. & Lists of items are provided wherever essential & & & 2.60 & & 86.67 \\
\hline 9. & Content is audible & & 2.67 & & & 88.89 \\
\hline 10. & Distracted with visual movement & 2.27 & & & & 75.56 \\
\hline 11. & Content is provided with no reasoning & & & 2.30 & & 76.67 \\
\hline 12. & Action verbs are not used & & & & 2.33 & 77.78 \\
\hline 13. & There is no repetition of key words & & 1.50 & & & 50.00 \\
\hline 14. & Font type, size, color and texture are accurate & & & 2.60 & & 86.67 \\
\hline 15. & No opportunity for experience and manipulation & & & & 2.23 & 74.44 \\
\hline 16. & Content is supported by music and sounds & & 2.70 & & & 90.00 \\
\hline 17. & Content is in textual form & 2.87 & & & & 95.56 \\
\hline 18. & $\begin{array}{l}\text { Problems and happenings are not presented in the } \\
\text { content }\end{array}$ & & 2.13 & & & 71.11 \\
\hline 19. & Highlights are specifically presented & & & 2.40 & & 80.00 \\
\hline 20. & Illustrated ideas in pictures & 2.63 & & & & 87.78 \\
\hline 21. & Promoting a feeling to note down important points & & & & 2.70 & 90.00 \\
\hline 22. & No distracting sounds and noise & & 2.57 & & & 85.56 \\
\hline 23. & Not maintained visual reminders & 1.53 & & & & 51.11 \\
\hline 24. & Generated interest to start physical action & & & & 2.63 & 87.78 \\
\hline
\end{tabular}

The maximum score for each item was 3 and thus, a total of 18 could be attained for each style. As depicted above, eight statements numbered 5, 10,11, 12, 13, 15, 18, and 23 are negative statements. The mean score and corresponding percentage of positive statements are indicative of agreement of the respondents, to the statement and for negative statements disagreement. The higher is the score for positive statements, the higher is the agreement. The lower the score for the negative statement, the lower is the agreement.

The statement with highest agreement was for the presentation of 'content in visual form' (95.56\%), and low 'for not highlighting the key points' $(75.56 \%)$. Other statements ranged between these two statements and hence, it can be inferred that, there was good agreement of VARK compatibility of ICT modules. 
Similarly, highest number disagreed for the statement number 5- 'content, is not described in understandable language and words' (83.33), and lowest for 13- 'no repetition of key words' (50.00\%), closely followed by 23 - 'not maintained visual reminders'(51.11\%). As lower/ higher the score for negative statements, lower the agreement of compatibility, the items 13 and 23 were to be modified, by repeating key words and maintaining visuals reminders.

It can also be inferred that, ICT module has the capability to instigate the learners, with different learning styles to learn.

As such, VARK learning style can create a fascinating learning environment, for learners and stimulate the senses for learning. According to Othman and Amiruddin (2010), VARK learning style does not involve intelligence or inherent skill, but is closely related to how one acquires or understands information or new knowledge. It can be perceived as an individual method that, one uses for the purpose of acquiring knowledge, positive skills and attitudes.

Salman (2006), opined that, it may not be possible to take into account, all the learning styles of each of the individual learner, but exposing learners to a variety of learning styles may be a more practical approach to help them use their intelligence to the maximum potential, and facilitate their learning.

Pani (2014), co-founder and CEO, Reverie Language Technologies felt the need for relevant and quality local language online content, translation and user interface technology, as well as mobile services, to further grow the vernacular services industry. Singh (2014), Vice President, Marketing and business development of Raftaar summarized that, consumers are more receptive to the content provided in vernacular languages, which provides users with information in various categories like entertainment, religion, news, sports and astrology etc., in vernacular languages. National Readership Survey (2006), reported non availability of vernacular ICT materials is an impediment, for knowledge sharing through a fastest and widest media. Rani (2014) and Priya (2011), found that, the tribal and rural leaners could be actively engaged in learning, due to the vernacular language. The ICT modules, which were tested for VARK learning style is in the vernacular, for its uploading at www.vigyanasaadhitha.com. Sijwali (2015), observed this vernacular web portal with good clicks and hits, and recommended for uploading the content through ICT modules helps many to visit and make use of it, for learning.

Guo (2013), stated the average engagement time of any video maxes out at 6 minutes, regardless of its length and engagement times, decrease as videos lengthen. To maximize student engagement, the lecture should be broken up into small, bite-sized pieces. Medhiet al. (2007) expressed voice annotation generally helps in speed of comprehension, but bimodal audio-visual information can be confusing for the target population. But, reported a mixed impact when added video animation and static imagery like photos and drawings.

In the present study, the ICT module on health and nutrition education, offered the content of leafy vegetables, millets, anemia, diabetes and thyroidism in the form of text, voice, images and videos. At the end, the respondents were to answer some questions. The compatibility mean scores were confirming the VARK style of the module. Apart from this, the language, the font type and size of the text and voice and its modulation also contribute the learning. Though they were not considered as variables for the present investigation, they play a significant role.

\section{CONCLUSIONS}

Experts judged the ICT modules, as possessing VARK compatibility through an observatory inventory, However, 
there were two negative statements, with low score compared to other items viz., 'no repetition of key words' and 'not maintained visual reminders', which are to be incorporated into ICT modules.

\section{REFERENCES}

1. Fleming, N. D. 2001. Teaching and learning styles: VARK strategies. Christchurch, New Zealand.

2. Guo, P. 2013. Optimal Video Length for Student Engagement. http://blog.edx.org/optimal-video-length-student-engagement.

3. Medhi, I., Prasad, A and Toyama, k. 2007.Optimal Audio-Visual Representations for Illiterate Users of Computers. Technology for Developing Regions. http://www2007.org/papers/paper764.pdf.

4. National Readership Survey (2006) what is National Readership Survey. http://articles.economictimes.indiatimes.com/20040105/news/27381554_1_nrs-national-readership-survey-council-sample-size

5. Othman, $N$ and Amiruddin, M.H. 2010. Different perspectives of learning styles from vark model. Faculty of Education, University Kebangsaan Malaysia, 43600 Bangi, Selangor, Malaysia.

6. Pani, A. 2014.Interview with Arvind Pani.http://www.crazyengineers.com/threads/interview-with-arvind-pani-co-founder-andceo-reverie-language-technologies.74023\%.

7. Priya,V, P. 2011. Effectiveness of Animated Modules of Nutrition Messages on High School Children; An Experimental Study.

8. Rani, S. 2014. Adolescent Reproductive Health (ARH) communication among tribal adolescent girls- an assessment and accomplishment through edutainment. Hyderabad. 35- 38.

9. Reid, J. M. 1987. The learning style preferences of ESL students. TESOL Quarterly 21(1):87-111.

10. Salman, A. 2006. How Adults Learn Facilitating Learning. Bahrain Medical Bulletin.28: 2.

11. Sijwali, S. 2015. Promotional Strategies for Web Portal.www.vigyanasaadhitha.com - An Experimental Study.

12. Singh, S.2014. http://www.raftaar.in/in-press/loksatta_june_06.

13. Siragusa, L and Dixon, K.C. 2008. Planned behavior: Student attitudes towards the use of ICT interactions in higher education.

14. Vijayaraghavan, K. 2002. Control of micronutrient deficiencies in India: obstacles and strategies. 60: (5 Pt 2)73-6. http://www.ncbi.nlm.nih.gov/pubmed/12035864.

15. Wright, S and Stokes, A. 2015. The application of VARK learning styles in introductory level economics units. Issues in Educational Research, 25(1), 62-79. 
